\title{
A Rare Anomaly of the Left Renal Vein in the Laboratory of Anatomy of Bamako (Mali)
}

\author{
Abdoulaye Kanté1,2, Babou Ba², Bréhima Bengaly1, Mariam Daou³, Bréhima Coulibaly1, \\ Drissa Ouattara1, Siaka Diakitée ${ }^{2}$, Moumouna Koné ${ }^{2}$, Tata Touré2, Cheickh Tidiane Diallo², \\ Ousmane Ibrahim Touré1, Drissa Traoré1, Nouhoum Ongoïba1,2*
}

${ }^{1}$ Service of Surgery B. CHU Point G, Bamako, Mali

${ }^{2}$ Laboratory of Anatomy of the Faculty of Medicine, Bamako, Mali

${ }^{3}$ Service of Neurology, CHU Gabriel Touré, Bamako, Mali

Email: kanteim@yahoo.fr

How to cite this paper: Kanté, A., Ba, B., Bengaly, B., Daou, M., Coulibaly, B., Ouattara, D., Diakité, S., Koné, M., Touré, T., Diallo, C.T., Touré, O.I., Traoré, D. and Ongoïba, N. (2019) A Rare Anomaly of the Left Renal Vein in the Laboratory of Anatomy of Bamako (Mali). Forensic Medicine and Anatomy Research, 7, 31-35. https://doi.org/10.4236/fmar.2019.71006

Received: October 15, 2018

Accepted: December 20, 2018

Published: January 22, 2019

Copyright (c) 2019 by authors and Scientific Research Publishing Inc. This work is licensed under the Creative Commons Attribution International License (CC BY 4.0).

http://creativecommons.org/licenses/by/4.0/ (c) (i) Open Access

\begin{abstract}
Aim: The purpose of this work was to describe the left renal retro-aortic vein. Methodology: A case of left renal retro-aortic vein was discovered on a corpse of male, 45-year-old adult during the dissections to the laboratory of anatomy of the Faculty of Medicine of Bamako. The way at first was a xypho-pubic median and two side abdominal sections under costal and inguinal. The side sections under costal went of the median section to sides by following the costal edge. The inguinal side sections went of the median section to the anterior and superior iliac thorns. The abdominal wall was opened and reclined by every quoted. The small intestine and the colonist were resected with their meso. The renal pedicle was dissected on each side. The abdominal aorta and the inferior vena cava were dissected by the diaphragm up to the headland. Arteries and iliac veins were also dissected. Results: On male corpse, 45 years old, we discovered a left renal retro-aortic vein in horizontal route, and the trunk of the left renal vein was formed by the confluence of three veins at the level of the left renal hilum. The left renal vein passed almost horizontally below the left renal artery. It passed then behind the abdominal aorta to end in the inferior vena cava at the level of its left side face. The right renal vein had a normal aspect. Conclusion: The left renal retro-aortic vein is one of the variants of the anomalies of the system cellar inferior. The left renal retro-aortic vein could be responsible for renal aplasia.
\end{abstract}

\section{Keywords}

Left Renal Retro-Aortic Vein, Anatomy, Retroperitoneal Surgery

\section{Introduction}

The left renal retro-aortic vein is the situation in which this vein crosses last one 
the abdominal aorta to throw itself into the inferior vena cava [1].

The inferior vena cava originates at the level of the fifth vertebra lombal (L5) of the confluence of both common iliac veins. It rises to the anterior-right side of the vertebral column, to the right of the abdominal aorta up to the ninth thoracic vertebra (T9) where it crosses the tendinous center of the diaphragm to end in the right atrium [2]. In its route, the inferior vena cava receives before crossing behind the liver, the renal veins right and left.

The left renal retro-aortic vein is a variant of the anomalies of the system cellar inferior whose frequency varies according to Anne [3] between $0.2 \%$ and 3\%. ICV abnormalities with renal retro-aortic vein are sometimes incidental peroperative discovery. They can be discovered during the anatomical dissections [4]. They can be highlighted following certain clinical demonstrations [5]. The knowledge of the anomalies of the inferior vena cava, particularly the left renal retro-aortic vein, is essential in the retroperitoneal surgery from the interest of this observation.

\section{Case Report}

It is about a male, 45-year-old corpse dissected in the laboratory of anatomy of the Faculty of Medicine of Bamako in the month of October 2017. The way at first was a xypho-pubic median and two side abdominal sections under costal and inguinal. The side sections under costal went of the median section to sides by following the costal edge. The inguinal side sections went of the median section to the anterior and superior iliac thorns. The abdominal wall was opened and reclined by every quoted (Figure 1 ).

The small intestine and the colonist were resected with their meso (Figure 2).

The renal changing room was dissected. For that purpose, the fat died renal was dissected minutely. The renal pedicle was dissected on each side. This dissection went of the hilum of the kidney up to the inferior vena cava. The fat around the renal vein and around the renal artery was resected. The abdominal aorta and the inferior vena cava were dissected by the diaphragm up to the headland.

This dissection was pursued towards the iliac region of lower $10 \mathrm{~cm}$ to individualize well arteries and iliac veins. After these dissections, vessels were photographed with a telephone Samsung Galaxia+.

During the dissection, we discovered (Figure 3):

- a left renal vein retro aortic in horizontal route,

o the trunk of the left renal vein formed by the confluence of three veins at the level of the left renal hilum,

0 in two $\mathrm{cm}$ of the hilum, the trunk of the left renal vein received the left adrenal vein .The left renal vein descended vertically, pre-existing the left renal artery to the left renal vein on its upper face.

o the left ovarian vein threw itself on the lower face of the left renal vein compared to the adrenal vein. 


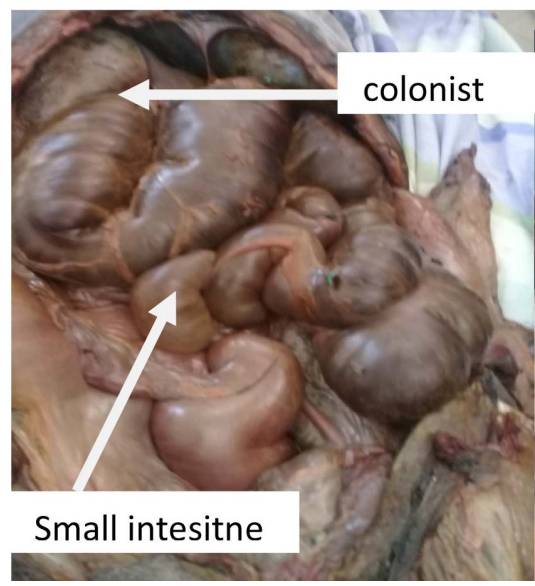

Figure 1. Showing ways at first.

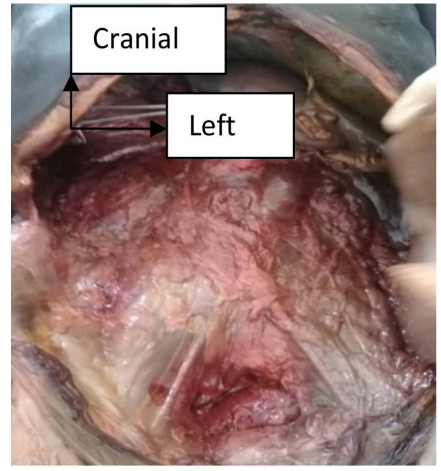

Liver

Figure 2. Showing abdominal cavity without intestinal handles.

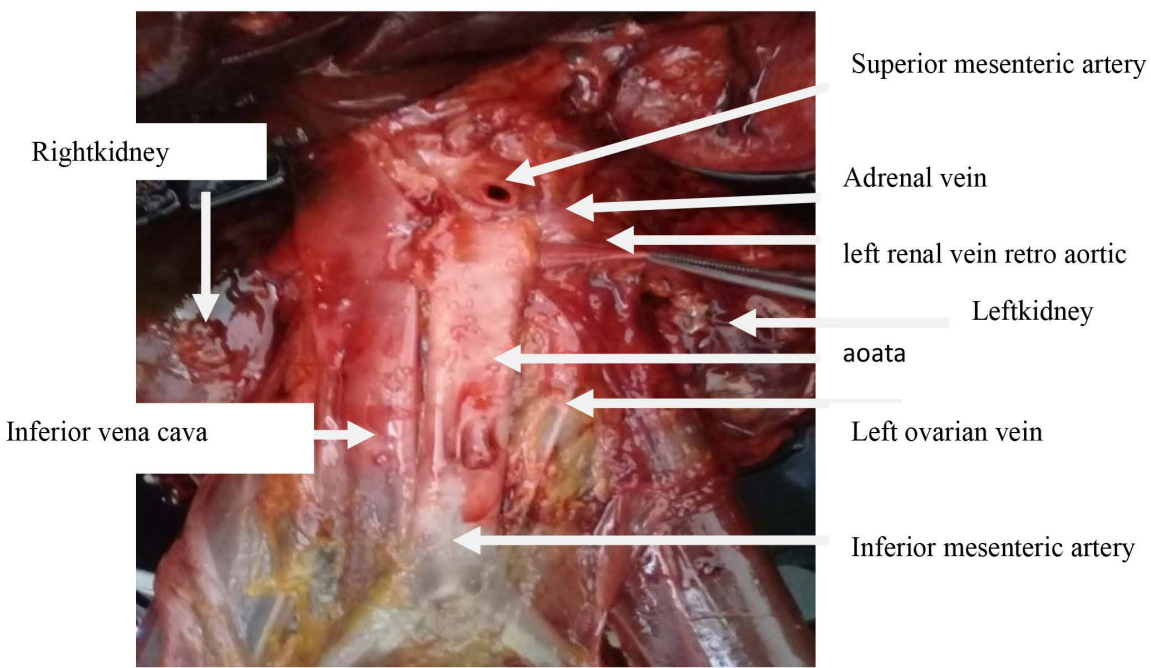

Figure 3. Showing the left aortic retro renal vein pulled by the clamp.

- The left renal vein passed almost horizontally below the left renal artery. It passed then behind the abdominal aorta to end in the inferior vena cava at the level of its left side face.

- The right renal vein had a normal aspect. 


\section{Discussion}

Our observation of left renal vein retro aortic is a rare case of anomaly of the system cellar inferior. According to Gayer [5] the left renal retro aortic vein could be at the origin of aplasia renal left. This renal aplasia could give some explanation easily by the difference of pressure between the abdominal aorta and the renal vein.

Indeed in the case of the left renal retro-aortic vein, the pressure of the abdominal aorta is going to hamper the return of the venous blood of the kidney. This embarrassment is more stressed by the weight of the aorta and the abdominal viscera if the subject is in dorsal decubitus. The venous return being hampered, the renal aplasia arises secondarily.

The left renal retro-aortic vein is a part of anomalies of the system cellar inferior which are very varied and give a complex. It is in touch with the complexity of the organogenesis of the inferior vena cava. The left renal retro-aortic vein can be associated with other affections in particular the aneurysm of the abdominal aorta [6].

It can return the cure of this difficult affection if the surgeon has no it preoperative, the information about the presence of this anomaly. The left renal vein can be drained in the inferior vena cava at the level of its face lower as in our observation or be connected in the system azygos at the level of the $3^{\text {rd }}$ lombale vertebra [7]. The left renal vein can connect at the level of the left common iliac vein $[8]$.

The renal vein is one of elements of the system cellar inferior whose formation is very complex. In the literature [1] [8] [9], several anatomical types are described whose left renal vein retro aortic. In the classification of Streeter and Orahilly quoted by Pillet, at the stag 12 (embryo from 2.6 to $4 \mathrm{~mm}$ is 26 days of life intra uterine), the venous drainage of caudal half of the embryo is made by the posterior cardinal veins. These cardinal veins receive segmental veins of the mesonephron.

At the stage $13-15$ (10 mm embryo or 28 in 30 days) it is the formation of veins sub-cardinals by longitudinal anastomosis of the veins segmental. At the stage 16 (11 $\mathrm{mm}$ embryo is 37 days) it is the anastomosis between the cardinal veins and subcardinales. Among this anastomosis there are the posterior branches and the previous branches. At the stage 18 ( $15 \mathrm{~mm}$ embryo is 44 days) the external nice veins are going to appear and form an anastomosis between the posterior cardinal system and the vein subcardinale. At this stage all the anastomosis is constituted.

In stages 19 and 21 some anastomosis are going to develop while others are going to disappear. Generally it is during these stages that the anomalies of the inferior vena cava are going to establish. Certain structures instead of atrophying are going to develop or conversely.

\section{Embryological Meaning of Our Observation}

The previous left anastomosis inter subcardinals atrophied. The left posterior 
anastomosis inter sub-cardinals developed to form the left renal vein which was in aortic retro position.

\section{Conclusion}

The left renal retro-aortic vein is one of the variants of the anomalies of the system cellar inferior. The extreme variability of the anomalies of this system is due to the complexity of the embryogenesis of the inferior vena cava. The left renal retro-aortic vein could be responsible for renal aplasia.

\section{Authorization of the Ethics Committee}

We, undersigned, authors of this article, give evidence to have received the authorization of the Ethics Committee of the Faculty of Medicine of Bamako.

\section{Conflicts of Interest}

We, authors of this article, declare that there is no conflict of interests.

\section{References}

[1] Pillet, J., Chevallier, J.M., Enon, B., Moreau, P., Cronier, P. and Haberdasher, P. (1983) The Organogenesis of the Lower Vena Cava. Arteries Veins, 2, 470-472.

[2] Chevallier, J.M. and Vitte, E. (2011) The Abdominal Cavity. In: Anatomy of the Trunk, 2nd Edition, Lavoisier, Paris, 169.

[3] Anne, N., Pallapothu, R. and Johnson, M.D. (2005) Inferior Vena Cave Duplication and Deep Venous Thrombosis: Case Report and Review of Literature. Annals of Vascular Surgery, 19, 740-743. https://doi.org/10.1007/s10016-005-5674-6

[4] Senecail, B., Bobeuf, J., Forlodou, P. and Noment, M. (2003) Two Rare Anomalies of the Left Renal Vein. Journal of Radio-Anatomy, 25, 465-467. https://doi.org/10.1007/s00276-003-0164-4

[5] Gayer, G., Zissin, R., Straiss, S. and Heartz, M. (2003) IVC Anomalies and Right Renal Aplasia Detected on CT: A Possible Link. Journal of Abdomen Imaging, 28, 395-399. https://doi.org/10.1007/s00261-002-0090-7

[6] Kudo, F.A., Nishibe, T., Miyazaki, K., Flores, J. and Yasuda, K. (2003) Left Renal Vein Anomaly Associated with Abdominal Aortic Aneuvrysm Surgery: Report of a Case. Surgery Today, 33, 609-611. https://doi.org/10.1007/s00595-003-2536-0

[7] Yoshinaga, K., Kawai, K. and Kodama, K. (2000) Anatomical Study of the Retroaortic Left Renal Vein. Journal of Anatomy in Japan, 77, 47-52.

[8] Broncatelli, G., Galia, M., Finazzo, M., Sparracia, G., Pardo, S. and Lagalla, R. (2000) Retroaortic Left Renal Vein Joining the Left Common Iliac Vein. European Journal of Radiology, 10, 1724-1725. https://doi.org/10.1007/s003300000383

[9] Langman, J., Sadier, T.W. and Pages, R. (1996) Medical Embryology. 6th Edition, Pradel, Paris, 196-248. 